OPEN ACCESS

Edited by: Maw Pin Tan

University of Malaya, Malaysia

Reviewed by:

Tomasz Grodzicki,

Jagiellonian University Medical

College, Poland

Renato Gorga Bandeira De Mello, Federal University of Rio Grande do

Sul, Brazi

*Correspondence:

Jie Tian

tianjie823_a@21cn.com

Specialty section

This article was submitted to

Geriatric Medicine

a section of the journal

Frontiers in Medicine

Received: 16 April 2021

Accepted: 07 July 2021

Published: 19 August 2021

Citation:

Wang P, Zhang S, Zhang K and Tian J

(2021) Frailty Predicts Poor Prognosis

of Patients After Percutaneous

Coronary Intervention: A

Meta-Analysis of Cohort Studies.

Front. Med. 8:696153.

doi: 10.3389/fmed.2021.696153

\section{Frailty Predicts Poor Prognosis of Patients After Percutaneous Coronary Intervention: A Meta-Analysis of Cohort Studies}

\author{
Peng Wang, Shutang Zhang, Ke Zhang and Jie Tian* \\ Department of Gerontology, Fuling Central Hospital of Chongqing City, Chongqing, China
}

Background: Frailty has been related to a higher risk of cardiovascular events, while the association between frailty and outcomes for patients with coronary artery disease (CAD) after percutaneous coronary intervention (PCI) remains unclear. We performed a meta-analysis of cohort studies to evaluate the above association.

Methods: Cohort studies aiming to determine the potential independent association between frailty and clinical outcomes after $\mathrm{PCl}$ were identified by search of PubMed, Embase, and Web of Science databases from inception to February 22, 2021. A random-effects model that incorporates the possible heterogeneity among the included studies was used to combine the results.

Results: Ten cohort studies with 7,449,001 patients were included. Pooled results showed that frailty was independently associated with higher incidence of all-cause mortality [adjusted risk ratio $(\mathrm{RR})=2.94,95 \%$ confidence intervals $(\mathrm{Cl}): 1.90-4.56, \mathrm{l}^{2}$ $=56 \%, P<0.001$ ] and major adverse cardiovascular events [(MACEs), adjusted RR $=$ 2.11, 95\% Cl: $\left.1.32-3.66, I^{2}=0 \%, P=0.002\right]$. Sensitivity analyses limited to studies including elderly patients showed consistent results (mortality: $\mathrm{RR}=2.27,95 \% \mathrm{Cl}$ : $1.51-3.41, I^{2}=23 \%, P<0.001$; MACEs: RR $=2.44,95 \% \mathrm{Cl}: 1.44-4.31, I^{2}=0 \%$, $P=0.001)$. Subgroup analyses showed that characteristics of study design, follow-up duration, or type of $\mathrm{PCl}$ did not seem to significantly affect the associations $(P$-values for subgroup analyses all $>0.05$ ).

Conclusions: Frailty may be an independent risk factor of poor prognosis for patients with CAD after PCl.

Keywords: frailty, percutaneous coronary intervention, mortality, major adverse cardiovascular events, meta-analysis

\section{BACKGROUND}

Currently, coronary artery disease (CAD) remains one of the most important causes of morbidity and mortality for global population, particularly for the elderly (1). Besides optimized medical treatment, early coronary revascularization has been established as the most effective therapy for alleviating symptoms and improving prognosis in patients with CAD (2). Due to the efficacy and invasiveness of the procedure, percutaneous coronary intervention 
(PCI) has become the most widely used method for coronary revascularization (3). For patients with acute CAD, such as STsegment elevation myocardial infarction (STEMI), primary PCI is recommended as early as possible to avoid the necrosis of myocardium (4). For patients with stable $\mathrm{CAD}$ and frequent symptom of angina, elective PCI is also recommended to restore the coronary blood flow for the ischemic myocardium (5). With the development of the devices and techniques, increasing elderly patients with CAD received PCI (6). According to previous studies, more than $20 \%$ of patients that received PCI are older than 75 years $(3,6)$. However, despite of the overall effectiveness of the procedure, adverse cardiovascular events or event deaths remain occur in some patients after PCI, which highlights the importance of risk stratification for CAD patients that received PCI (7).

Frailty is a geriatric syndrome characterized by age-related decrease of reserve capacity of various systems and lack of resilience to stressors (8). Accumulating evidence suggests that frailty is related to poor prognosis of patients with various cardiovascular conditions, such as acute myocardial infarction (AMI) (9), congestive heart failure (10, 11), atrial fibrillation (12), and for patients after transcatheter aortic valve implantation (13). However, the association between frailty and the prognosis of patients after PCI remains unclear (14). Most studies showed that frailty is independently associated with higher risk of mortality and adverse events after PCI (15-22), while some did not (23, 24). Accordingly, a previous meta-analysis included eight cohort studies and showed that frailty was associated with a higher risk of death for patients after PCI (25). However, two of the cohort studies actually included patients who did not receive PCI $(26,27)$. Besides, this meta-analysis included studies with univariate analysis and a study using continuous gait speed as the indicator of frailty (28), which made the results of the metaanalysis difficult to interpret. Since several relevant cohort studies $(17-22,24)$ have been published since the previous meta-analysis, we aimed to perform an updated meta-analysis to summarize the current understanding for the association between frailty and prognosis after PCI.

\section{METHODS}

The Meta-analysis of Observational Studies in Epidemiology (MOOSE) guideline (29) and Cochrane's Handbook (30) was followed in this study.

\section{Literature Search}

The electronic databases of PubMed, Embase, and Web of Science databases were searched from inception to February 22, 2021 with a strategy of combined terms including (1) "frailty" OR "frail;" and (2) "percutaneous coronary intervention" OR "stent" OR "angioplasty" OR "revascularization" OR "reperfusion" OR PCI. Only studies reported in English were considered. References of related articles or reviews were also analyzed. The full search term for PubMed database was based on keywords as [("frailty" OR "frail") AND ("coronary artery disease" OR "angina” OR "myocardial infarction" OR "acute coronary syndrome" OR "percutaneous coronary intervention"
OR "major adverse cardiovascular events" OR "CAD” OR “STEMI” OR “NSTEMI” OR “ACS” OR “AMI” OR “PCI”)].

\section{Study Identification}

Studies fulfilled these criteria were used: (1) cohort studies published as full-length papers; (2) included adult patients with CAD; (3) frailty was evaluated during the index hospitalization for PCI and considered as exposure; (4) compared the incidence of all-cause mortality and/or major adverse cardiovascular events (MACEs) between patients with and without frailty during follow-up; and (4) reported risk ratios (RRs) for the above associations after adjusting for multiple confounding factors (at least for age and sex). Methods for the assessment of frailty were in accordance with those applied in the original articles. We defined MACEs as a composite outcome of all-cause death, non-fatal myocardial infarction (MI), non-fatal stroke, repeated coronary revascularization, and cardiac readmission. Reviews, preclinical studies, cross-sectional studies, and irrelevant studies were not included.

\section{Data Extracting and Quality Evaluation}

Two authors implemented database search, data extraction, and study quality assessment separately. If disagreements occurred, they were discussed with the corresponding author. These data were recorded: (1) author, country, and study design characteristics; (2) characteristics of the patients, including the diagnosis, number of participants included, mean age, and sex; (3) methods for the evaluation of frailty and number of patients with frailty at baseline; (4) PCI type and follow-up durations; (5) outcomes reported; and (6) potential confounding factors adjusted in the multivariate analyses for the association. The Newcastle-Ottawa Scale (31) was used for study quality evaluation. This scale is rated from 1 to 9 stars and reflected the quality of the study by aspects of participant selection, comparability between groups, and outcome validation.

\section{Statistical Analyses}

RRs and the corresponding 95\% confidence intervals (CIs) were extracted for every included study. Then, standard errors (SEs) of RRs were estimated from the $95 \% \mathrm{CIs}$ or $P$-values. For normalization of their distribution, HRs were logarithmically transformed (30) and combined. Heterogeneity within the included cohort studies was tested via Cochrane's Q-test, as well as the estimation of $I^{2}$ statistic (32). An $I^{2}>50 \%$ suggests significant level of heterogeneity. A random-effects model was chosen to combine the RRs by incorporating the potential heterogeneity within studies (30). Sensitivity analyses by sequentially excluding either of the included studies were conducted to clarify the influence of a certain study on the overall results (33). Predefined subgroup analyses according to study design, follow-up duration, and type of PCI were also performed. Funnel plots were constructed, and were used for the assessment of publication bias (34). Visually asymmetrical funnel plots implied potential publication bias, which could be further validated by the Egger's regression asymmetry test. If high risk of publication bias was suggested, a "trim-and-fill" analysis was used for further evaluation, which estimates the influence of possible 


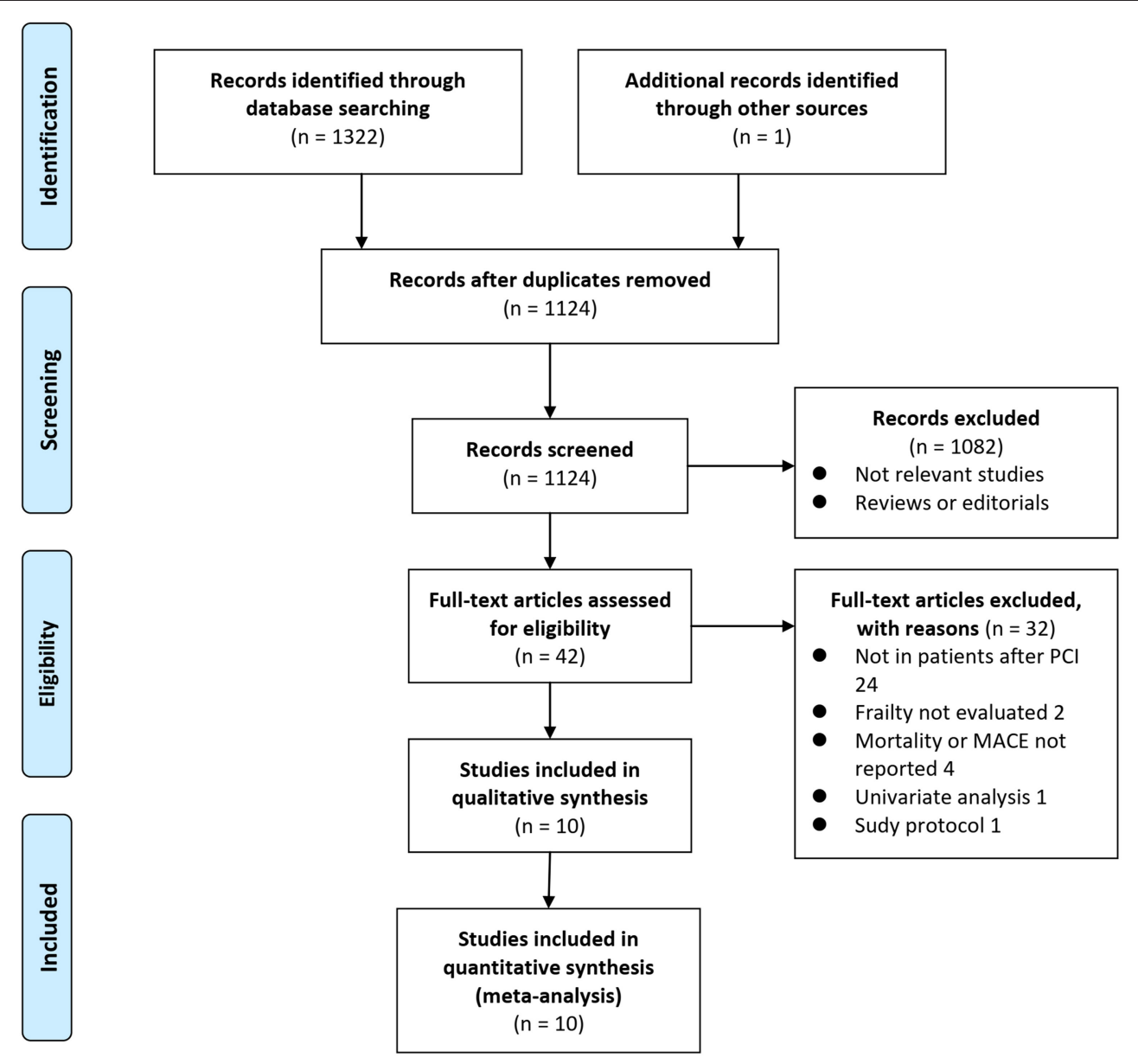

FIGURE 1 | Scheme of study inclusion.

studies with negative findings on the meta-analysis outcome (30). The RevMan (Version 5.1; Cochrane Collaboration, Oxford, UK) and STATA software were involved for statistical analyses.

\section{RESULTS}

\section{Database Search}

Details of the database search are shown in Figure 1. The firststep database search retrieved 1,124 articles after duplicated studies were excluded. Among them, 1,082 studies were further excluded because they were not related to the purpose of the meta-analysis based on titles and abstracts. Then, for the remaining 42 studies evaluated by full text reading, 32 were not included for the reasons presented in Figure 1, which resulted in ten cohort studies finally analyzed in the meta-analysis (15-24).

\section{Study Characteristics}

Characteristics of each study of the meta-analysis are shown in Table 1. Overall, ten cohort studies with 7,449,001 patients were considered to be eligible for the meta-analysis (15-24), which were performed in the United States $(15,19)$, United Kingdom (16, 17, 24), Spain (18), Japan (21, 22), and Indonesia (23), respectively. Five of them were prospective (15-18, 23), and the rest were retrospective $(19-22,24)$. Three studies included patients with unselected CAD $(15,16,24)$, the others included patients with stable CAD (23), non-ST segment elevation acute coronary syndrome (NSTE-ACS) (17), and ST-elevation myocardial infarction (18-22), respectively. The mean ages of the included patients varied between 62 and 85 years, with proportions of males varying from 46 to $75 \%$. Multiple tools were used for the evaluation of frailty among the included studies, including the Fried Frailty Criteria $(15,17)$, the Canadian Study of Health and Aging Clinical Frailty Scale $(16,22)$, validated frailty phenotype criteria (23), FRAIL scale (18), Claims-based Frailty Index (19), Safety Management Programme Score (20), Hospital Frailty Risk Score (24), and modified KATZ index (21). A total of 16,183 patients were considered with frailty at baseline. All the patients included in these studies received primary or elective PCI procedures. The follow-up durations varied from within hospitalization to 35 months after PCI. Incidence of all-cause mortality was reported in eight studies $(15,16,18-$ 22, 24), and incidence of MACEs was reported in five studies $(15,17,20,23,24)$. Age, sex, body mass index, risk factors for $\mathrm{CAD}$, comorbidities, and coronary lesion features were adjusted 
TABLE 1 | Characteristic of the included studies.

\begin{tabular}{|c|c|c|c|c|c|c|c|c|c|c|c|c|}
\hline Study & Country & Design & $\begin{array}{l}\text { Patient } \\
\text { characteristics }\end{array}$ & $\begin{array}{l}\text { Sample } \\
\text { size }\end{array}$ & $\begin{array}{l}\text { Mean age } \\
\text { (years) }\end{array}$ & Male (\%) & Frailty evaluation & $\begin{array}{l}\text { No. of } \\
\text { patients with } \\
\text { frailty }\end{array}$ & PCl type & $\begin{array}{l}\text { Follow-up } \\
\text { duration } \\
\text { (months) }\end{array}$ & Outcomes & Variables adjusted \\
\hline Singh et al. (15) & USA & PC & $\begin{array}{l}\text { CAD patients } \geq 65 \\
\text { years who underwent } \\
\text { PCl }\end{array}$ & 629 & 69.0 & 74.3 & $\begin{array}{l}\text { Using the Fried } \\
\text { Frailty Criteria } \\
\text { during index } \\
\text { hospitalization }\end{array}$ & 117 & $\begin{array}{l}\text { Primary or } \\
\text { elective }\end{array}$ & 35 & $\begin{array}{l}\text { All-cause mortality } \\
\text { and MACE }\end{array}$ & $\begin{array}{l}\text { Age, sex, Mayo Clinic } \\
\text { Risk Score, Charlson } \\
\text { Comorbidity Index, and } \\
\text { Short-form-36 }\end{array}$ \\
\hline $\begin{array}{l}\text { Murali-Krishnan } \\
\text { et al. (16) }\end{array}$ & UK & PC & $\begin{array}{l}\text { CAD patients who } \\
\text { underwent } \mathrm{PCl}\end{array}$ & 746 & 62.2 & 70.1 & $\begin{array}{l}\text { Using the } \\
\text { Canadian Study of } \\
\text { Health and Aging } \\
\text { Clinical Frailty } \\
\text { Scale during } \\
\text { hospitalization }\end{array}$ & 81 & $\begin{array}{l}\text { Primary or } \\
\text { elective }\end{array}$ & 12 & All-cause mortality & $\begin{array}{l}\text { Age, sex, } \\
\text { hemodynamically } \\
\text { instability, CHF, DM, } \\
\text { COPD, renal failure, and } \\
\text { TIA/stroke }\end{array}$ \\
\hline $\begin{array}{l}\text { Hamonangan } \\
\text { et al. (23) }\end{array}$ & Indonesia & $\mathrm{PC}$ & $\begin{array}{l}\text { Stable CAD patients } \geq \\
60 \text { years who } \\
\text { underwent } \mathrm{PCl}\end{array}$ & 100 & 70.0 & 69.0 & $\begin{array}{l}\text { Using frailty } \\
\text { phenotype criteria } \\
\text { during } \\
\text { hospitalization }\end{array}$ & 61 & Elective & 1 & MACE & $\begin{array}{l}\text { Age, sex and } \\
\text { comorbidities }\end{array}$ \\
\hline Calvo et al. (18) & Spain & $\mathrm{PC}$ & $\begin{array}{l}\text { STEMl patients } \geq 75 \\
\text { years who underwent } \\
\text { primary PCl }\end{array}$ & 259 & 82.6 & 57.9 & $\begin{array}{l}\text { Using FRAlL scale } \\
\text { during } \\
\text { hospitalization }\end{array}$ & 51 & Primary & In-hospitalization & All-cause mortality & $\begin{array}{l}\text { Age, sex, LVEF, number } \\
\text { of vessels diseased, } \\
\text { and Barthel index }\end{array}$ \\
\hline Batty et al. (17) & UK & PC & $\begin{array}{l}\text { NSTEACS patients } \geq \\
75 \text { years who } \\
\text { underwent } \mathrm{PCl}\end{array}$ & 280 & 81.0 & 60.0 & $\begin{array}{l}\text { Using Fried Frailty } \\
\text { Index during } \\
\text { hospitalization }\end{array}$ & 77 & Elective & 12 & MACE & $\begin{array}{l}\text { Age, sex, SBP, Killip } \\
\text { Class, history of PVD, } \\
\text { and BMS use }\end{array}$ \\
\hline $\begin{array}{l}\text { Damluji et al. } \\
\text { (19) }\end{array}$ & USA & $\mathrm{RC}$ & $\begin{array}{l}\text { STEMl patients } \geq 75 \\
\text { years who underwent } \\
\text { primary PCl }\end{array}$ & 140,089 & 80.9 & 51.0 & $\begin{array}{l}\text { Using } \\
\text { Claims-based } \\
\text { Frailty Index during } \\
\text { hospitalization }\end{array}$ & 13,855 & Primary & In-hospitalization & All-cause mortality & $\begin{array}{l}\text { Age, sex, and } \\
\text { comorbidities }\end{array}$ \\
\hline $\begin{array}{l}\text { Hermans et al. } \\
\text { (20) }\end{array}$ & $\begin{array}{l}\text { The } \\
\text { Netherlands }\end{array}$ & $\mathrm{RC}$ & $\begin{array}{l}\text { STEMI patients } \geq 70 \\
\text { years who underwent } \\
\text { primary PCl }\end{array}$ & 206 & 79.0 & 58.0 & $\begin{array}{l}\text { Using Safety } \\
\text { Management } \\
\text { Programme Score } \\
\text { during } \\
\text { hospitalization }\end{array}$ & 57 & Primary & 1 & $\begin{array}{l}\text { All-cause mortality } \\
\text { and MACE }\end{array}$ & $\begin{array}{l}\text { Age, sex, CAD risk } \\
\text { factors, comorbidities, } \\
\text { and treatments }\end{array}$ \\
\hline $\begin{array}{l}\text { Yoshioka et al. } \\
\text { (22) }\end{array}$ & Japan & $\mathrm{RC}$ & $\begin{array}{l}\text { STEMI patients } \geq 80 \\
\text { years who underwent } \\
\text { primary PCl }\end{array}$ & 273 & 84.6 & 46.2 & $\begin{array}{l}\text { Using the } \\
\text { Canadian Study of } \\
\text { Health and Aging } \\
\text { Clinical Frailty } \\
\text { Scale at admission }\end{array}$ & 34 & Primary & 24 & All-cause mortality & $\begin{array}{l}\text { Age, sex, CAD risk } \\
\text { factors, comorbidities, } \\
\text { and coronary lesion } \\
\text { features }\end{array}$ \\
\hline Kwok et al. (24) & UK & $\mathrm{RC}$ & $\begin{array}{l}\text { CAD patients who } \\
\text { underwent } \mathrm{PCl}\end{array}$ & 730,6007 & 66.1 & 65.3 & $\begin{array}{l}\text { Using a validated } \\
\text { Hospital Frailty } \\
\text { Risk Score during } \\
\text { hospitalization }\end{array}$ & 1,836 & $\begin{array}{l}\text { Primary or } \\
\text { elective }\end{array}$ & In-hospitalization & $\begin{array}{l}\text { All-cause mortality } \\
\text { and MACE }\end{array}$ & $\begin{array}{l}\text { Age, sex, Charlson } \\
\text { Comorbidity Index, and } \\
\text { coronary lesion features }\end{array}$ \\
\hline $\begin{array}{l}\text { Seguchi et al. } \\
\text { (21) }\end{array}$ & Japan & $\mathrm{RC}$ & $\begin{array}{l}\text { STEMl patients } \geq 80 \\
\text { years who underwent } \\
\text { primary PCl }\end{array}$ & 412 & 84.5 & 60.0 & $\begin{array}{l}\text { Using the modified } \\
\text { KATZ index during } \\
\text { hospitalization }\end{array}$ & & Primary & In-hospitalization & All-cause mortality & $\begin{array}{l}\text { Age, sex, Killip Class, } \\
\text { hemoglobin, } \\
\text { comorbidities, and } \\
\text { treatments }\end{array}$ \\
\hline
\end{tabular}

PCI, percutaneous coronary intervention; PC, prospective cohort; RC, retrospective cohort; CAD, coronary artery disease; STEMI, ST-segment elevation myocardial infarction; NSTE-ACS, non-ST-segment elevation acute coronary syndrome; MACE, major adverse cardiovascular events; CHF, congestive heart failure; DM, diabetes mellitus; COPD, chronic obstructive pulmonary disease; TIA, transient ischemia attack; LVEF, left ventricular ejection fraction; SBP, systolic blood pressure; PVD, peripheral vascular disease; BMS, bare-metal stent. 
to a varying degree when the associations between frailty and outcomes after PCI were reported. The quality of these studies was good, evidenced by six to nine points of NOS scores (Table 2).

\section{Association Between Frailty and All-Cause Mortality After PCI}

Eight studies $(15,16,18-22,24)$ reported the outcome of allcause mortality after PCI. Moderate heterogeneity was detected among the included studies ( $P$ for Cochrane's $Q$-test $=0.02$, $I^{2}=56 \%$ ). Pooled results with a random-effect model showed that frailty was independently associated with a higher incidence of all-cause mortality (adjusted RR $=2.94,95 \%$ CI: $1.90-4.56$, $P<0.001$; Figure 2A). Sensitivity analyses by excluding one study at a time showed similar results (RR: $2.33-3.54, P$ all $<0.05$ ). Sensitivity analysis only including studies with elderly patients $(15,18-22)$ showed consistent results (adjusted RR = 2.27, 95\% CI: 1.51-3.41, $P<0.001)$, and the heterogeneity was substantially reduced ( $\mathrm{P}$ for Cochrane's $Q$-test $=0.26, I^{2}=23 \%$ ). Subgroup analyses showed that the association between frailty and increased risk of all-cause mortality in patients with CAD after PCI was not significantly affected by characteristics of study design (prospective or retrospective), follow-up duration (within or more than 1 month), or type of PCI (primary or elective; $P$-values for subgroup analyses all $>0.05$; Figures 2B-D).

\section{Association Between Frailty and MACEs After PCI}

Five studies $(15,17,20,23,24)$ reported the outcome of MACEs. No significant heterogeneity was detected ( $P$ for Cochrane's $Q-$ test $\left.=0.80, I^{2}=0 \%\right)$. Pooled results showed that frailty was independently associated with a higher incidence of MACEs (adjusted RR $=2.11,95 \% \mathrm{CI}: 1.32-3.66, P=0.002$; Figure 3A). Sensitivity analyses by excluding one study at a time showed similar results (RR: $1.92-2.44, P$ all $<0.05)$. Sensitivity analysis limited to studies with elderly patients $(15,17,20,23)$ also showed consistent results (adjusted RR $=2.44$, 95\% CI: $1.44-$ 4.13, $P=0.001 ; I^{2}=0 \%$ ). Subgroup analyses also showed that characteristics of study design, follow-up duration, or type of PCI did not significantly affect the association $(P$-values for subgroup analyses all $>0.05$; Figures 3B-D).

\section{Publication Bias}

Funnel plots representing the meta-analyses for the associations between frailty and all-cause mortality after PCI were shown in Figure 4A. The plots for the outcome of all-cause mortality were asymmetrical based on visual inspection, raising the possible publication bias (Figure 4A). Egger's regression test also demonstrated potential risk of publication bias $(P=0.048)$. We therefore performed a trim-and-fill analysis. As shown in Figure 4A, incorporating a hypothesized study achieved symmetry of the funnel plots, and the results of the metaanalysis remained significant after including the study (adjusted $\mathrm{RR}=2.80$, 95\% CI: $\left.1.83-4.27, P<0.001 ; I^{2}=52 \%\right)$. Funnel plots representing the meta-analyses for the associations between frailty and MACEs after PCI were shown in Figure 4B. These plots were symmetrical judged by visual inspection, reflecting

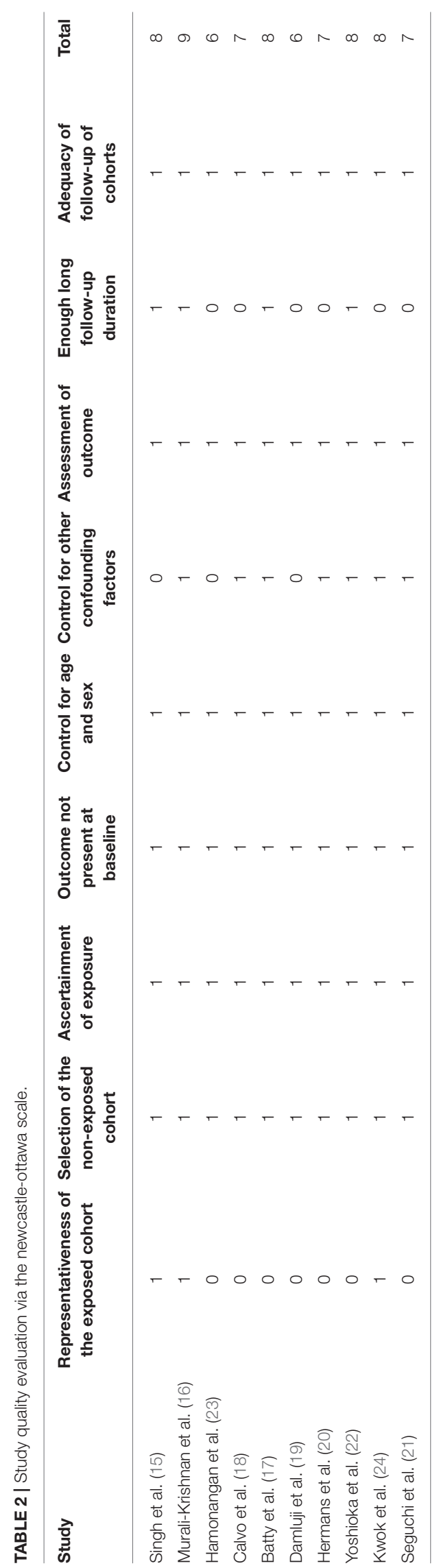




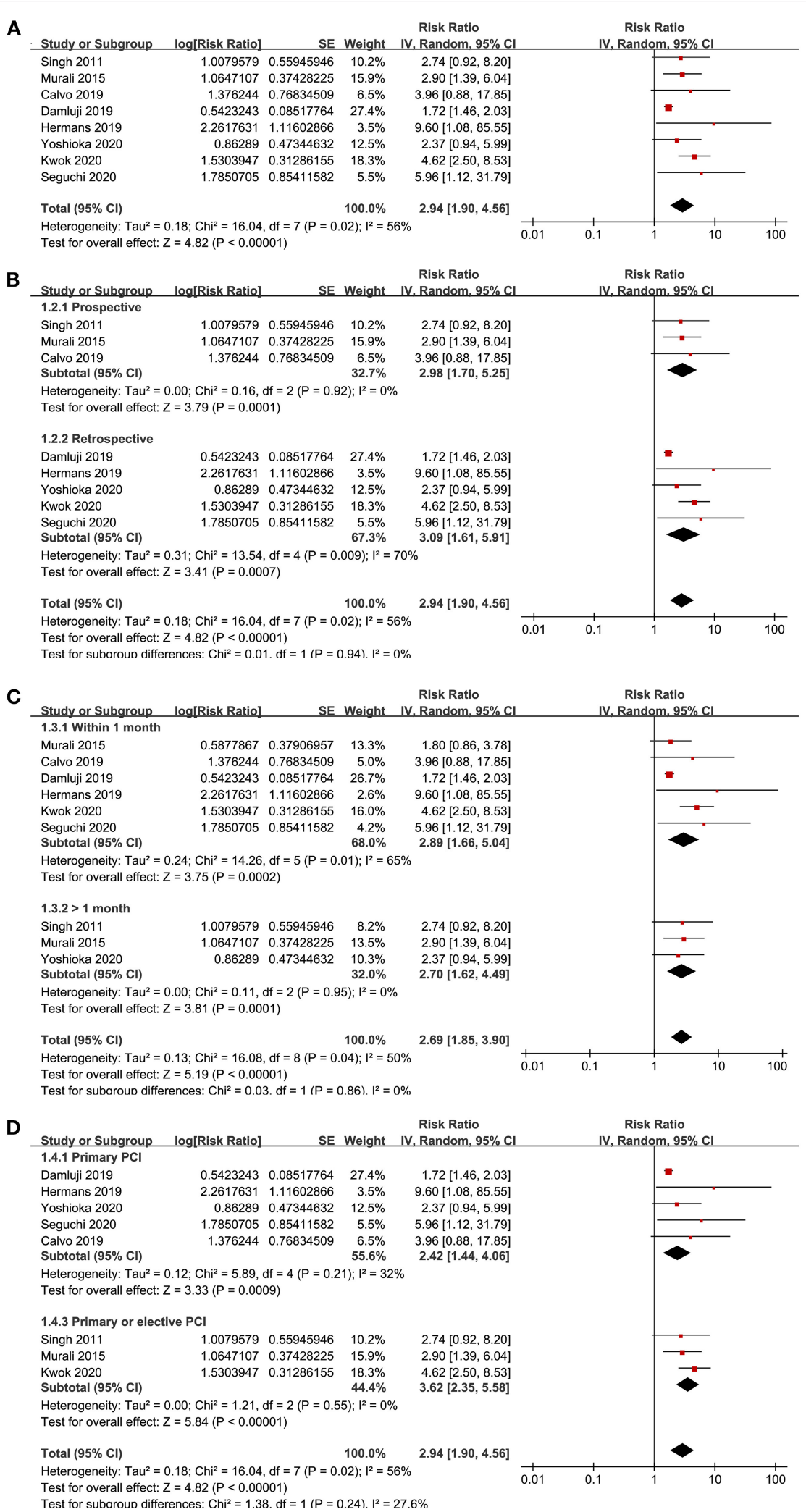

FIGURE 2 | Forest plots for the meta-analysis concerning the association between frailty and risk of all-cause mortality after PCl; (A), Overall meta-analysis; (B), Subgroup analysis according to study design; (C), Subgroup analysis according to follow-up duration; and (D), Subgroup analysis according to the type of PCI. 
A

\begin{tabular}{lrrr} 
& & & \\
Study or Subgroup & log[Risk Ratio] & SE & Weight \\
\hline Singh 2011 & 0.896088 & 0.38298219 & $38.8 \%$ \\
Hamonangan 2016 & 0.4054651 & 1.02512267 & $5.4 \%$ \\
Batty 2019 & 0.8796267 & 0.54460055 & $19.2 \%$ \\
Hermans 2019 & 1.0647107 & 0.61611018 & $15.0 \%$ \\
Kwok 2020 & 0.2231436 & 0.51191054 & $21.7 \%$ \\
& & & $100.0 \%$ \\
Total (95\% Cl) & & $10.12 \%$ \\
Heterogeneity: Tau ${ }^{2}=0.00 ;$ Chi $^{2}=1.63$, df $=4(P=0.80) ; I^{2}=0 \%$ \\
Test for overall effect: $Z=3.13(P=0.002)$ &
\end{tabular}

Random, 95\% Cl

$2.11[1.32,3.36]$

SE Weight IV. Random. $95 \% \mathrm{Cl}$

B

\begin{tabular}{lrrr} 
Study or Subgroup & log[Risk Ratio] & SE & Weigh \\
\hline 1.6.1 Prospective & & & \\
Singh 2011 & 0.896088 & 0.38298219 & $38.8 \%$ \\
Hamonangan 2016 & 0.4054651 & 1.02512267 & $5.4 \%$ \\
Batty 2019 & 0.8796267 & 0.54460055 & $19.2 \%$ \\
Subtotal $(95 \% \mathrm{Cl})$ & & & 63.3 \\
Heterogeneity: Tau $^{2}=0.00 ; \mathrm{Chi}^{2}=0.21, \mathrm{df}=2(\mathrm{P}=0.90)$ & $\mathrm{I}^{2}=$
\end{tabular}

Heterogeneity: $\mathrm{Tau}^{2}=0.00 ; \mathrm{Chi}^{2}=0.21, \mathrm{df}=2(\mathrm{P}=0.90) ; 1^{2}=0 \%$

Test for overall effect: $Z=2.83(P=0.005)$

1.6.2 Retrospective

Hermans 2019

Kwok 2020

$\begin{array}{lll}1.0647107 & 0.61611018 & 15.0 \%\end{array}$ $0.2231436 \quad 0.51191054 \quad 21.7 \%$

$\begin{array}{lll}0.2231436 & 0.51191054 & 21.7 \% \\ & & 36.7 \%\end{array}$

Subtotal $(95 \% \mathrm{Cl})$

Heterogeneity: $\mathrm{Tau}^{2}=0.03 ; \mathrm{Chi}^{2}=1.10, \mathrm{df}=1(\mathrm{P}=0.29) ; \mathrm{I}^{2}=9 \%$

Test for overall effect: $Z=1.38(P=0.17)$

Total $(95 \% \mathrm{Cl})$

$100.0 \%$

Heterogeneity: $\mathrm{Tau}^{2}=0.00 ; \mathrm{Chi}^{2}=1.63, \mathrm{df}=4(\mathrm{P}=0.80) ; \mathrm{I}^{2}=0 \%$

Test for overall effect: $Z=3.13(P=0.002)$

Test for subaroun differences: $\mathrm{Ch}^{2}=0.29 . \mathrm{df}=1(\mathrm{P}=0.59) . \mathrm{I}^{2}=0 \%$

C

Study or Subgroup

Hamonangan 2016

Hermans 2019

Kwok 2020

Subtotal $(95 \% \mathrm{Cl})$

Heterogeneity: $\mathrm{Tau}^{2}=0.00 ; \mathrm{Chi}^{2}=1.13, \mathrm{df}=2(P=0.57) ; \mathrm{l}^{2}=0 \%$

Test for overall effect: $Z=1.49(P=0.14)$

1.7.2 $>1$ month

Singh 2011

Batty 2019

Subtotal $(95 \% \mathrm{Cl})$

$0.8796267 \quad 0.54460055 \quad 19.2 \%$

$57.9 \%$

Heterogeneity: $\mathrm{Tau}^{2}=0.00 ; \mathrm{Chi}^{2}=0.00, \mathrm{df}=1(\mathrm{P}=0.98) ; \mathrm{I}^{2}=0 \%$

Test for overall effect: $Z=2.84(P=0.004)$

Total $(95 \% \mathrm{Cl})$

$100.0 \%$

Heterogeneity: $\mathrm{Tau}^{2}=0.00 ; \mathrm{Chi}^{2}=1.63, \mathrm{df}=4(\mathrm{P}=0.80) ; \mathrm{I}^{2}=0 \%$

Test for overall effect: $Z=3.13(P=0.002)$

Test for subaroun differences: $\mathrm{Chi}^{2}=0.51 . \mathrm{df}=1(\mathrm{P}=0.48) . \mathrm{I}^{2}=0 \%$

D

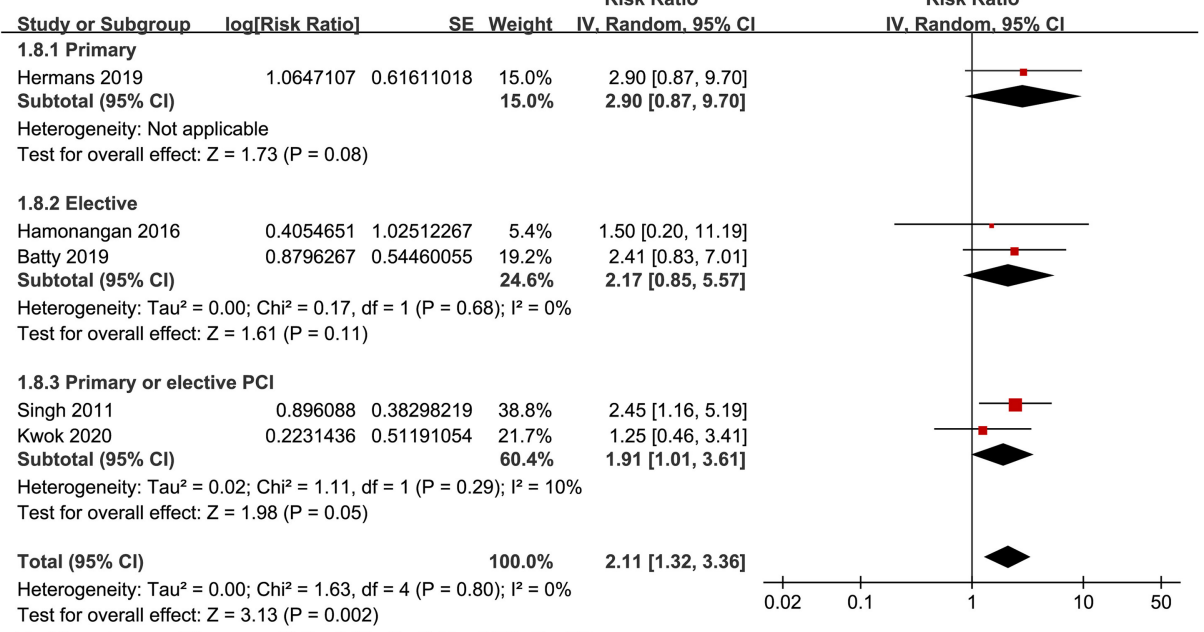

Risk Ratio

$2.45[1.16,5.19]$

$1.50[0.20,11.19]$

$2.41[0.83,7.01]$

$2.90[0.87,9.70]$

$1.25[0.46,3.41]$

Risk Ratio

Risk Ratio

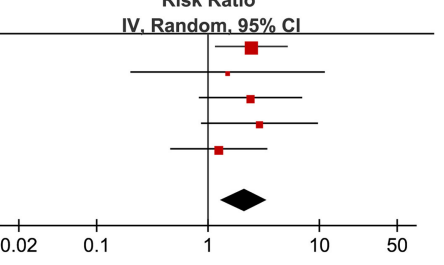

Risk Ratio

$2.45[1.16,5.19]$

$1.50[0.20,11.19]$

$2.41[0.83,7.01]$

$2.34[1.30,4.21]$

IV. Random. 95\% C

IV. Random. $95 \%$ Cl

$2.90[0.87,9.70]$

$1.25[0.46,3.41]$

$1.78[0.79,4.00]$

$2.11[1.32,3.36]$

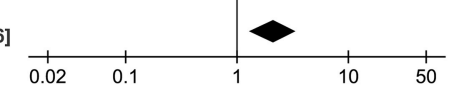

Risk Ratio

V. Random. $95 \% \mathrm{Cl}$

Risk Ratio IV. Random. $95 \% \mathrm{Cl}$

$1.50[0.20,11.19]$ $2.90[0.87,9.70]$

$1.25[0.46,3.41]$

$1.73[0.84,3.55]$

IV. Random, $95 \% \mathrm{Cl}$

$2.45[1.16,5.19]$

$2.41[0.83,7.01]$

$2.44[1.32,4.50]$

$2.11[1.32,3.36]$

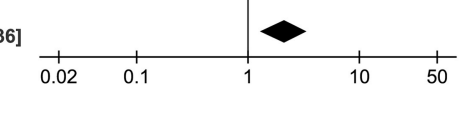

Risk Ratio
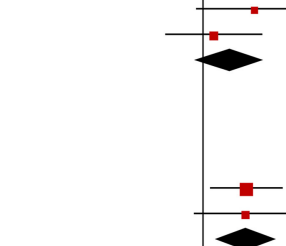

Test for subaroun differences: $\mathrm{Chi}^{2}=0.37 . \mathrm{df}=2(\mathrm{P}=0.83) . \mathrm{I}^{2}=0 \%$

FIGURE 3 | Forest plots for the meta-analysis concerning the association between frailty and risk of MACEs after PCl; (A), Overall meta-analysis; (B), Subgroup analysis according to study design; (C), Subgroup analysis according to follow-up duration; and (D), Subgroup analysis according to the type of PCl. 
low possibility of publication bias. Egger's regression test was not performed because only five datasets were analyzed for this outcome.

\section{DISCUSSION}

In this meta-analysis of cohort studies, we found that frailty was independently associated with higher incidences of morality and MACEs in patients with CAD after PCI. Sensitivity analyses showed that the significance of the results was not affected by omitting of either of the included studies. Besides, sensitivity analyses limited to studies including elderly patients with CAD showed consistent results. Moreover, results of subgroup analyses showed that the association between frailty and poor prognosis after PCI was not significantly affected by study characteristics such as study design, follow-up duration, and type of PCI. Although risk of publication bias was noticed for the metaanalysis of the association between frailty and all-cause mortality after PCI, results of trim-and-fill analysis by incorporating the imputed study with negative result showed consistent results. Taken together, results of these findings indicated that frailty may be an independent risk factor for poor prognosis in patients with CAD who were treated with PCI.

A previous meta-analysis published in 2017 also showed that frailty may be associated with higher mortality risk for CAD patients after PCI (25). However, several weaknesses regarding the methodology of the meta-analysis have been noticed, which may affect the interpretation of the results. Besides of studies published as full-length articles that underwent peer-review, this meta-analysis has also included studies published in conference abstracts, which may introduce bias to the results. Moreover, this meta-analysis included two studies that not all of the included patients were treated with PCI $(26,27)$. In addition, one study with frailty measured via gait speed as a continuous variable was also introduced into the meta-analysis, which may confound the results of the meta-analysis (28). Compared to this study, our meta-analysis has several strengths. Firstly, only studies published as full-length articles were included. Secondly, all of the studies included patients with CAD who were treated with PCI. Thirdly, comparisons for the incidence of adverse clinical outcomes were directly made between patients with and without frailty. Moreover, besides all-cause mortality, outcome of MACEs was also evaluated. In addition, only studies with multivariate analyses were considered, which therefore could indicate a potentially independent association between frailty and poor outcomes after PCI. Finally, multiple sensitivity and subgroup analyses were performed, which showed consistent results in elderly patients, in studies with different design, followup durations, and types of PCI.

The potential mechanisms underlying the association between frailty and poor outcomes after PCI remain not fully understood. It has been shown that frail patients may have longer recovery time after invasive procedures (16), suggesting these patients may suffer from more post-procedure complications (23). Moreover, frailty has been associated with endothelial dysfunction (35) and activated inflammatory response (36), two key molecular

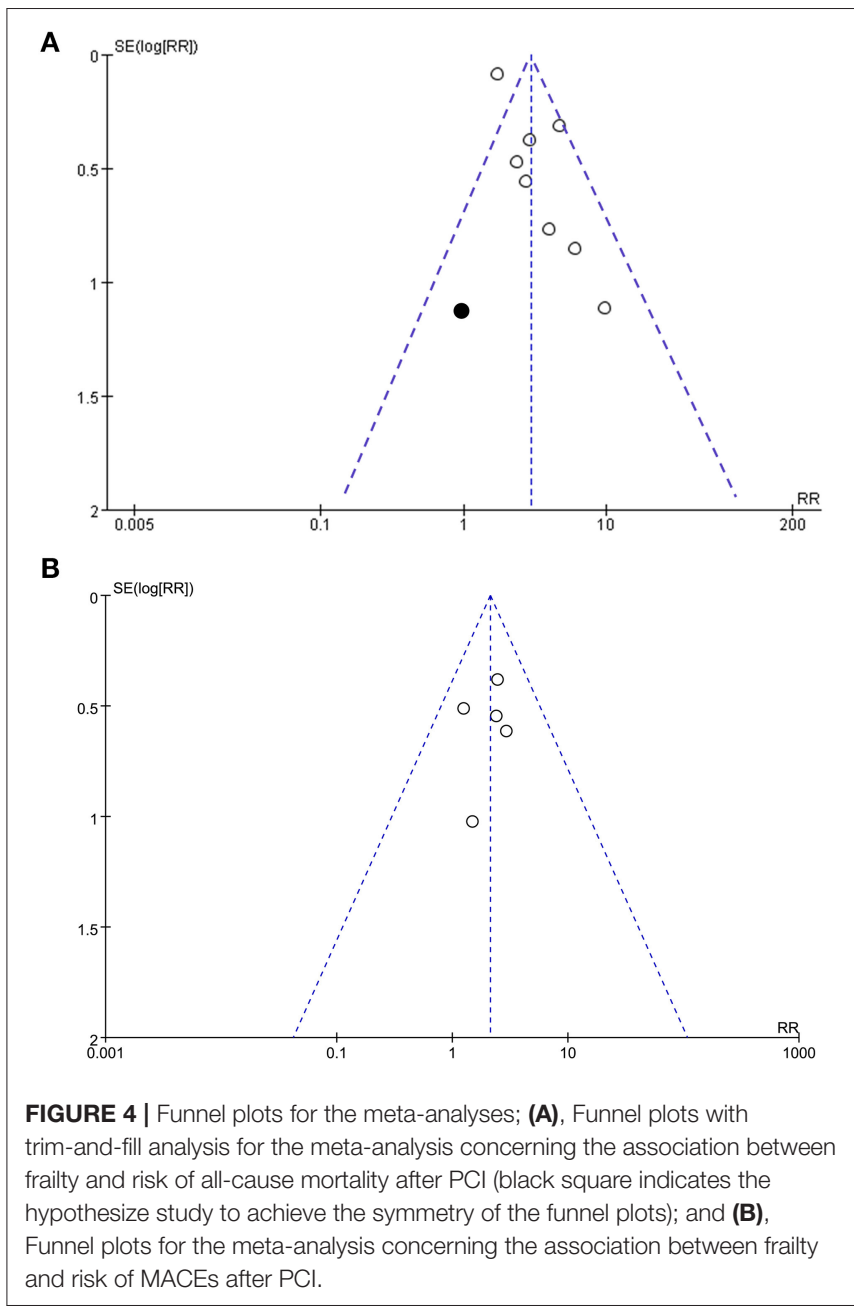

mechanisms underlying the adverse events after PCI, such as in-stent restenosis $(37,38)$. In addition, in a recent study in elderly Chinese CAD patients after PCI, frailty has been related to high on-aspirin platelet response and high on-clopidogrel platelet response among, a validated independent risk factor of thrombotic events after PCI (39). Further studies are warranted to evaluate the exact mechanisms involved in the association between frailty and poor prognosis after PCI.

It has to be mentioned that although we found that patients with frailty may have increased risk of mortality and MACEs after PCI, it does not mean that PCI should be avoided in patients with frailty. In fact, it was shown that STEMI patients with frailty had reduced hospital mortality after PCI as compared to those who received conservative treatments only (19). Since we have shown that frailty may be an independent risk factor for poor prognosis after PCI, it could be hypothesized that whether strategies alleviating frailty in these patients could provide additional clinical benefits after PCI. Studies are needed for further investigations.

This study also has limitations. Firstly, the meta-analysis was not registered at PROSPERO prospectively, but we followed 
the predefined protocol during the performance of the study. Secondly, the meta-analysis was not based on data from the study level but not from individual patients, which prevented further analyses on the influence of patient characteristics on the outcome. In addition, significant heterogeneity was detected for the meta-analysis of the association between frailty and mortality after PCI. Although sensitivity analysis limited to studies including elderly patients only significant reduced the heterogeneity ( $I^{2}$ from 56 to $23 \%$ ), we could not determine whether other factors contribute to the residual heterogeneity. Moreover, multiple scales were used for measurement of frailty, and we could not determine whether difference among these scales may affect the association between frailty and outcomes after PCI. Finally, possible risk of publication bias was raised in the meta-analysis regarding the association between frailty and poor prognosis after PCI. However, further trim-and-fill analysis suggested that the potential publication bias was not likely to affect the finding.

In conclusion, this updated meta-analysis of cohort studies suggested that frailty may be an independent risk factor of poor prognosis for patients with CAD after PCI. Future studies are needed to determine the optimal measurement tool for frailty

\section{REFERENCES}

1. Virani SS, Alonso A, Aparicio HJ, Benjamin EJ, Bittencourt MS, Callaway $\mathrm{CW}$, et al. Heart disease and stroke statistics-2021 update: a report from the American heart association. Circulation. (2021) 143:e254743. doi: 10.1161/CIR.0000000000000950

2. Gu D, Qu J, Zhang H, Zheng Z. Revascularization for coronary artery disease: principle and challenges. Adv Exp Med Biol. (2020) 1177:75100. doi: 10.1007/978-981-15-2517-9_3

3. Guo L, Lv HC, Huang RC. Percutaneous coronary intervention in elderly patients with coronary chronic total occlusions: current evidence and future perspectives. Clin Interv Aging. (2020) 15:771-81. doi: 10.2147/CIA.S252318

4. Levine GN, Bates ER, Blankenship JC, Bailey SR, Bittl JA, Cercek B, et al. 2015 ACC/AHA/SCAI focused update on primary percutaneous coronary intervention for patients with ST-elevation myocardial infarction: an update of the $2011 \mathrm{ACCF} / \mathrm{AHA} / \mathrm{SCAI}$ guideline for percutaneous coronary intervention and the 2013 ACCF/AHA guideline for the management of ST-elevation myocardial infarction: a report of the American college of cardiology/American heart association task force on clinical practice guidelines and the society for cardiovascular angiography and interventions. Circulation. (2016) 133:1135-47. doi: 10.1161/CIR.0000000000000336

5. Al-Lamee RK, Nowbar AN, Francis DP. Percutaneous coronary intervention for stable coronary artery disease. Heart. (2019) 105:11-9. doi: 10.1136/heartjnl-2017-312755

6. Shanmugam VB, Harper R, Meredith I, Malaiapan Y, Psaltis PJ. An overview of PCI in the very elderly. J Geriatr Cardiol. (2015) 12:174-84. doi: 10.11909/j.issn.1671-5411.2015.02.012

7. Baldasseroni S, Pratesi A, Orso F, Forte AL, Baroncini AC, Lucarelli G, et al. Role of frailty on risk stratification in cardiac surgery and procedures. Adv Exp Med Biol. (2020) 1216:99-113. doi: 10.1007/978-3-030-33330-0_11

8. Martin FC, O'halloran AM. Tools for assessing frailty in older people: general concepts. Adv Exp Med Biol. (2020) 1216:919. doi: 10.1007/978-3-030-33330-0_2

9. Putthapiban P, Vutthikraivit W, Rattanawong P, Sukhumthammarat W, Kanjanahattakij N, Kewcharoen J, et al. Association of frailty with allcause mortality and bleeding among elderly patients with acute myocardial infarction: a systematic review and meta-analysis. J Geriatr Cardiol. (2020) 17:270-78. doi: 10.11909/j.issn.1671-5411.2020.05.006 for patients undergoing PCI, and to evaluate whether strategies to attenuate frailty could provide additional clinical benefits in these patients.

\section{DATA AVAILABILITY STATEMENT}

The original contributions presented in the study are included in the article/supplementary material, further inquiries can be directed to the corresponding authors.

\section{AUTHOR CONTRIBUTIONS}

PW and JT designed the study. PW and SZ performed literature search, study quality evaluation, and data extraction. PW and KZ performed statistical analyses. PW, SZ, and KZ interpreted the results. PW drafted the manuscript. All authors contributed to the article and approved the submitted version.

\section{FUNDING}

This study was supported by Chongqing Clinical Research Center for Geriatric Diseases.

10. Zhang Y, Yuan M, Gong M, Li G, Liu T, Tse G. Associations between prefrailty or frailty components and clinical outcomes in heart failure: a follow-up meta-analysis. J Am Med Dir Assoc. (2019) 20:509-10. doi: 10.1016/j.jamda.2018.10.029

11. Marengoni A, Zucchelli A, Vetrano DL, Aloisi G, Brandi V, Ciutan $\mathrm{M}$, et al. Heart failure, frailty, and pre-frailty: a systematic review and meta-analysis of observational studies. Int J Cardiol. (2020) 316:16171. doi: 10.1016/j.ijcard.2020.04.043

12. Wilkinson C, Todd O, Clegg A, Gale CP, Hall M. Management of atrial fibrillation for older people with frailty: a systematic review and meta-analysis. Age Ageing. (2019) 48:196-203. doi: 10.1093/ageing/ afy 180

13. Anand A, Harley C, Visvanathan A, Shah ASV, Cowell J, Maclullich $A$, et al. The relationship between preoperative frailty and outcomes following transcatheter aortic valve implantation: a systematic review and meta-analysis. Eur Heart J Qual Care Clin Outcomes. (2017) 3:12332. doi: 10.1093/ehjqcco/qcw030

14. Bebb O, Smith FG, Clegg A, Hall M, Gale CP. Frailty and acute coronary syndrome: a structured literature review. Eur Heart J Acute Cardiovasc Care. (2018) 7:166-75. doi: 10.1177/2048872617700873

15. Singh M, Rihal CS, Lennon RJ, Spertus JA, Nair KS, Roger VL. Influence of frailty and health status on outcomes in patients with coronary disease undergoing percutaneous revascularization. Circ Cardiovasc Qual Outcomes. (2011) 4:496-502. doi: 10.1161/CIRCOUTCOMES.111.961375

16. Murali-Krishnan R, Iqbal J, Rowe R, Hatem E, Parviz Y, Richardson $\mathrm{J}$, et al. Impact of frailty on outcomes after percutaneous coronary intervention: a prospective cohort study. Open Heart. (2015) 2:e000294. doi: 10.1136/openhrt-2015-000294

17. Batty J, Qiu W, Gu S, Sinclair H, Veerasamy M, Beska B, et al. One-year clinical outcomes in older patients with non-ST elevation acute coronary syndrome undergoing coronary angiography: an analysis of the ICON1 study. Int J Cardiol. (2019) 274:45-51. doi: 10.1016/j.ijcard.2018.09.086

18. Calvo E, Teruel L, Rosenfeld L, Guerrero C, Romero M, Romaguera R, et al. Frailty in elderly patients undergoing primary percutaneous coronary intervention. Eur J Cardiovasc Nurs. (2019) 18:132-9. doi: 10.1177/1474515118796836

19. Damluji AA, Huang J, Bandeen-Roche K, Forman DE, Gerstenblith G, Moscucci M, et al. Frailty among older adults with acute myocardial infarction 
and outcomes from percutaneous coronary interventions. J Am Heart Assoc. (2019) 8:e013686. doi: 10.1161/JAHA.119.013686

20. Hermans MPJ, Eindhoven DC, Van Winden L, a.M., De Grooth GJ, Blauw GJ, et al. Frailty score for elderly patients is associated with short-term clinical outcomes in patients with ST-segment elevated myocardial infarction treated with primary percutaneous coronary intervention. Neth Heart J. (2019) 27:127-33. doi: 10.1007/s12471-019-1240-7

21. Seguchi M, Sakakura K, Tsukui T, Yamamoto K, Taniguchi Y, Wada H, et al. Determinants of in-hospital death among the very elderly with acute myocardial infarction. Int Heart J. (2020) 61:879-87. doi: 10.1536/ihj.20-165

22. Yoshioka N, Takagi K, Morishima I, Morita Y, Uemura Y, Inoue Y, et al. Influence of preadmission frailty on short- and mid-term prognoses in octogenarians with ST-elevation myocardial infarction. Circ J. (2020) 84:10918. doi: 10.1253/circj.CJ-19-0467

23. Hamonangan R, Wijaya IP, Setiati S, Harimurti K. Impact of frailty on the first 30 days of major cardiac events in elderly patients with coronary artery disease undergoing elective percutaneous coronary intervention. Acta Med Indones. (2016) 48:91-8.

24. Kwok CS, Achenbach S, Curzen N, Fischman DL, Savage M, Bagur R, et al. Relation of frailty to outcomes in percutaneous coronary intervention. Cardiovasc Revasc Med. (2020) 21:811-8. doi: 10.1016/j.carrev.2019.11.009

25. Tse G, Gong M, Nunez J, Sanchis J, Li G, Ali-Hasan-Al-Saegh S, et al. Frailty and mortality outcomes after percutaneous coronary intervention: a systematic review and meta-analysis. J Am Med Dir Assoc. (2017) 18:e1097.e1e10. doi: 10.1016/j.jamda.2017.09.002

26. Sujino Y, Tanno J, Nakano S, Funada S, Hosoi Y, Senbonmatsu T, et al. Impact of hypoalbuminemia, frailty, and body mass index on early prognosis in older patients ( $>/=85$ years) with ST-elevation myocardial infarction. $J$ Cardiol. (2015) 66:263-8. doi: 10.1016/j.jjcc.2014.12.001

27. Sanchis J, Ruiz V, Bonanad C, Valero E, Ruescas-Nicolau MA, Ezzatvar Y, et al. Prognostic value of geriatric conditions beyond age after acute coronary syndrome. Mayo Clin Proc. (2017) 92:934-9. doi: 10.1016/j.mayocp.2017.01.018

28. Matsuzawa Y, Konishi M, Akiyama E, Suzuki H, Nakayama N, Kiyokuni $\mathrm{M}$, et al. Association between gait speed as a measure of frailty and risk of cardiovascular events after myocardial infarction. J Am Coll Cardiol. (2013) 61:1964-72. doi: 10.1016/j.jacc.2013.02.020

29. Stroup DF, Berlin JA, Morton SC, Olkin I, Williamson GD, Rennie D, et al. Meta-analysis of observational studies in epidemiology: a proposal for reporting. Meta-analysis of observational studies in epidemiology (MOOSE) group. JAMA. (2000) 283:2008-12. doi: 10.1001/jama.283.15.2008

30. Higgins J, Green S. Cochrane Handbook for Systematic Reviews of Interventions Version 5.1.0. The Cochrane Collaboration (2011). Available online at: www.cochranehandbook.org (accessed March 1, 2021).

31. Wells GA, Shea B, O'connell D, Peterson J, Welch V, Losos M, et al. The Newcastle-Ottawa Scale (NOS) for Assessing the Quality of Nonrandomised
Studies in Meta-Analyses. (2010). Available online at: http://www.ohri.ca/ programs/clinical_epidemiology/oxford.asp (accessed March 1, 2021).

32. Higgins JP, Thompson SG. Quantifying heterogeneity in a meta-analysis. Stat Med. (2002) 21:1539-58. doi: 10.1002/ sim. 1186

33. Patsopoulos NA, Evangelou E, Ioannidis JP. Sensitivity of betweenstudy heterogeneity in meta-analysis: proposed metrics and empirical evaluation. Int $J$ Epidemiol. (2008) 37:1148-57. doi: 10.1093/ije/ dyn065

34. Egger M, Davey Smith G, Schneider M, Minder C. Bias in metaanalysis detected by a simple, graphical test. BMJ. (1997) 315:62934. doi: 10.1136/bmj.315.7109.629

35. Amarasekera AT, Chang D, Schwarz P, Tan TC. Does vascular endothelial dysfunction play a role in physical frailty and sarcopenia? A systematic review. Age Ageing. (2020) 50:725-32. doi: 10.1093/ageing/afaa237

36. Soysal P, Arik F, Smith L, Jackson SE, Isik AT. Inflammation, frailty and cardiovascular disease. Adv Exp Med Biol. (2020) 1216:55-64. doi: 10.1007/978-3-030-33330-0 7

37. Munk PS, Butt N, Larsen AI. Endothelial dysfunction predicts clinical restenosis after percutaneous coronary intervention. Scand Cardiovasc J. (2011) 45:139-45. doi: 10.3109/14017431.2011.564646

38. Demirtas K. Inflammation and in-stent restenosis. Angiology. (2018) 69:89. doi: 10.1177/0003319717722103

39. Liu Y, Liu S, Wang K, Liu H. Association of frailty with antiplatelet response among elderly chinese patients with coronary artery disease undergoing percutaneous coronary intervention. Clin Appl Thromb Hemost. (2020) 26:1076029620915994. doi: 10.1177/1076029620915994

Conflict of Interest: The authors declare that the research was conducted in the absence of any commercial or financial relationships that could be construed as a potential conflict of interest.

Publisher's Note: All claims expressed in this article are solely those of the authors and do not necessarily represent those of their affiliated organizations, or those of the publisher, the editors and the reviewers. Any product that may be evaluated in this article, or claim that may be made by its manufacturer, is not guaranteed or endorsed by the publisher.

Copyright (c) 2021 Wang, Zhang, Zhang and Tian. This is an open-access article distributed under the terms of the Creative Commons Attribution License (CC BY). The use, distribution or reproduction in other forums is permitted, provided the original author(s) and the copyright owner(s) are credited and that the original publication in this journal is cited, in accordance with accepted academic practice. No use, distribution or reproduction is permitted which does not comply with these terms. 